\title{
Radiation-induced angiosarcoma (RIAS) of the maxilla: a case report
}

\author{
Tae-Ho Kim¹, Chul-Hwan Kim¹, Sang-Gyu Choi ${ }^{1}$ \\ ${ }^{\prime}$ Department of Oral and Maxillofacial Surgery, College of Dentistry, Dankook University, \\ ${ }^{2}$ Department of Radiation Oncology, Dankook University College of Medicine, Cheonan, Korea
}

\begin{abstract}
J Korean Assoc Oral Maxillofac Surg 2020;46:288-291)
Angiosarcoma is a rare malignant mesenchymal tumor of vascular or lymphatic origin and represents less than $1 \%$ of all malignant tumors. Radiation therapy is a standard treatment in many head and neck cancer cases, but ionizing radiation is associated with radiation carcinogenesis including radiation-induced angiosarcoma. In this article, we report a rare case of radiation-induced angiosarcoma found in a 58-year-old female patient who was previously diagnosed with an odontogenic keratocyst and mucoepidermoid carcinoma.
\end{abstract}

Key words: Radiation-induced angiosarcoma, Radiation carcinogenesis, Mucoepidermoid carcinoma, Odontogenic keratocyst, Angiosarcoma [paper submitted 2019. 12. 27 / accepted 2020. 2. 26]

\section{Introduction}

Angiosarcoma is an extremely rare malignant mesenchymal tumor of vascular or lymphatic origin ${ }^{1}$. This type of tumor represent less than $1 \%$ of all malignant tumors, and about $50 \%$ of angiosarcomas are found in the head and neck region, with only approximately $1 \%$ reported to occur in the oral cavity or salivary glands ${ }^{1,2}$. Angiosarcoma most commonly affects the elderly and is predominant in males, with a male to female ratio of $2: 1^{3}$. Angiosarcoma is an extremely aggressive malignancy, with a predicted 5 -year survival rate for cases in the head and neck region of only $10 \%$ to $35 \%$. Optimal treatment includes extensive surgery and wide-field postoperative radiation therapy (RT). In this paper, we report a case of angiosarcoma that transformed from mucoepidermoid carcinoma as a result of RT, in a female patient originally diagnosed with an odontogenic keratocyst (OKC).

\section{Chul-Hwan Kim}

Department of Oral and Maxillofacial Surgery, College of Dentistry, Dankook University, 119 Dandae-ro, Dongnam-gu, Cheonan 31116, Korea TEL: +82-41-550-0271 FAX: +82-41-551-8988

E-mail:kimchoms@dankook.ac.kr

ORCID: https://orcid.org/0000-0002-5199-2420

(c) This is an open-access article distributed under the terms of the Creative Commons Attribution Non-Commercial License (http://creativecommons.org/ licenses/by-nc/4.0/), which permits unrestricted non-commercial use, distribution, and reproduction in any medium, provided the original work is properly cited.

Copyright (C) 2020 The Korean Association of Oral and Maxillofacial Surgeons. All rights reserved.

\section{Case Report}

A 58-year-old female visited Dankook University Dental Hospital (Cheonan, Korea) in January 2004, with complaints of facial swelling and gingival soreness. Swelling and pain of the right palatal area were found upon initial clinical examination. Computed tomography (CT) showed an extensive cystic lesion in the right maxilla and maxillary sinus. A clinical diagnosis of an OKC was made based on the patient's history and clinical observations. Enucleation and iliac bone graft were performed under general anesthesia subsequent to endodontic treatment of teeth $\# 13, \# 14, \# 15$, \#16, and \#17. Biopsy results revealed respiratory mucosa with chronic inflammation, fibrosis, and old hemorrhage.

In September 2006, a similar lesion was observed on follow-up CT radiographs, and a clinical diagnosis of recurrent OKC was made, but a biopsy of the mass revealed mucoepidermoid carcinoma. Partial maxillectomy under general anesthesia was performed, and adjuvant postoperative RT of 6,660 cGy in 37 fractions was subsequently initiated in November 2006.

However, in September 2018, the patient returned to our hospital with a brown tumor-like lesion in the right partial maxillectomy area. Incisional biopsy revealed malignancy that was suspicious for a malignant vascular tumor. Proton emission tomography-computed tomography (PET/CT) showed a lobulating hypermetabolic lesion (SUL max 20.9) approximately $5 \mathrm{~cm}$ in diameter and positioned within and 
around the right maxillary and nasal cavity area.(Fig. 1) Hemi-maxillectomy via the Weber Ferguson approach under general anesthesia was performed (Fig. 2) with no conjunc-

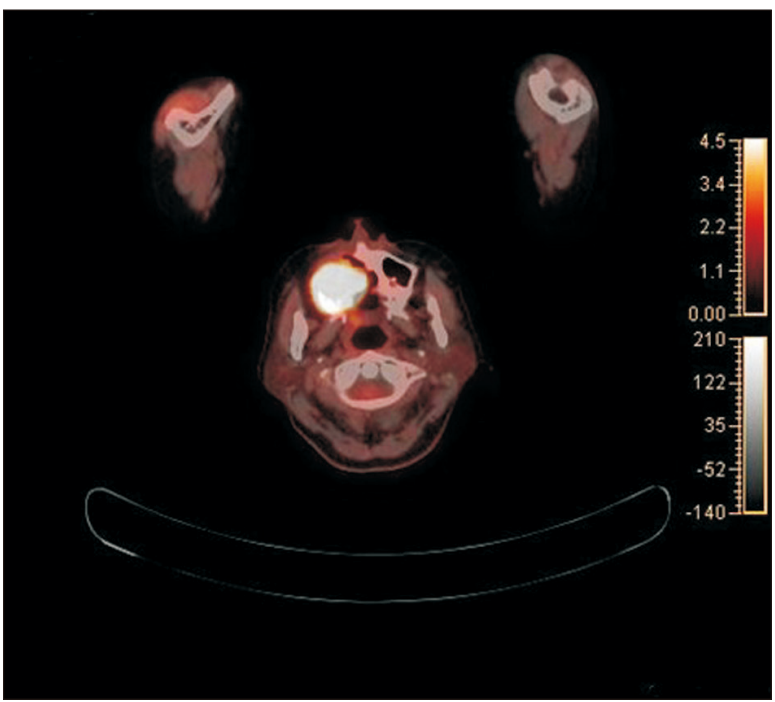

Fig. 1. Proton emission tomography-computed tomography showing hypermetabolic lesion around right maxilla and nasal cavity.

Tae-Ho Kim et al: Radiation-induced angiosarcoma (RIAS) of the maxilla: a case report. J Korean Assoc Oral Maxillofac Surg 2020 tive neck dissection, and the excised tumor was approximately $6 \mathrm{~cm}$ in diameter. Adjuvant RT of 6,000 cGy in 30 fractions was performed subsequent to surgery. To date, no specific symptoms or signs of recurrence have been found. Histologically, the tumor was composed of atypical spindle cells with hyperchromatic nuclei. The tumor also showed vascular formation that contained red blood cells.(Fig. 3) Immunohistochemical study revealed tumor cells that were positive for FLI-1 and INI-1.(Fig. 4) A pathological diagnosis of poorly differentiated, high-grade angiosarcoma of the maxilla was made. Based on the clinical, radiological, and pathological findings, the patient was finally diagnosed with radiationinduced angiosarcoma.

\section{Discussion}

$\mathrm{OKC}$ is an aggressive benign cyst that has a marked tendency for recurrence. Recurrence rates after excision are reported to range from $12 \%$ to $62.5 \%$. Histologic examination of recurrent cysts is seldom suggestive of premalignant or malignant changes, and frank malignant degeneration is rare ${ }^{5}$. However, the lining of an odontogenic cyst, including an $\mathrm{OKC}$, may transform into squamous cell carcinoma (SCCa)
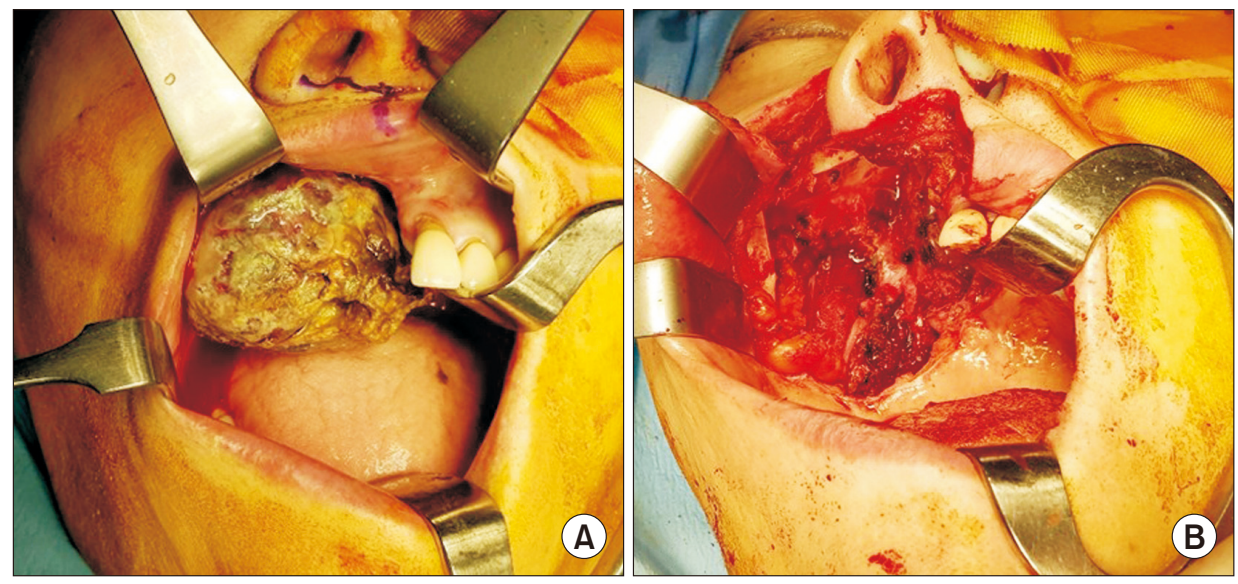

Fig. 2. A. Preoperative photograph of angiosarcoma in palate. B. Postoperative photograph of angiosarcoma in palate after resection.

Tae-Ho Kim et al: Radiation-induced angiosarcoma (RIAS) of the maxilla: a case report. J Korean Assoc Oral Maxillofac Surg 2020
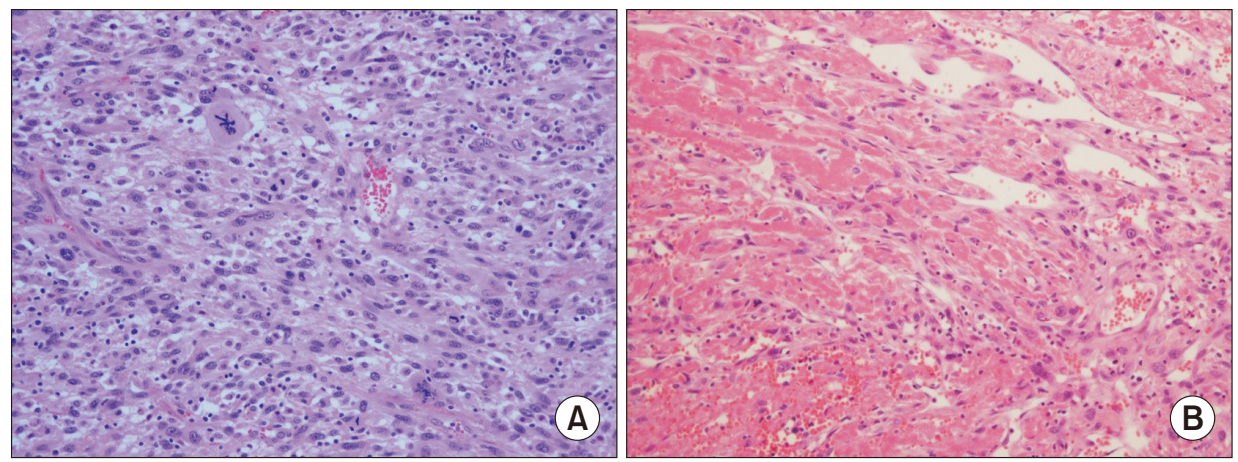

Fig. 3. A. Most of the cells show atypical spindle shape with hyperchromatic nuclei (H\&E staining, $\times 200)$. B. This area shows vascular formation (H\&E staining, $\times 200$ ).

Tae-Ho Kim et al: Radiation-induced angiosarcoma (RIAS) of the maxilla: a case report. J Korean Assoc Oral Maxillofac Surg 2020 

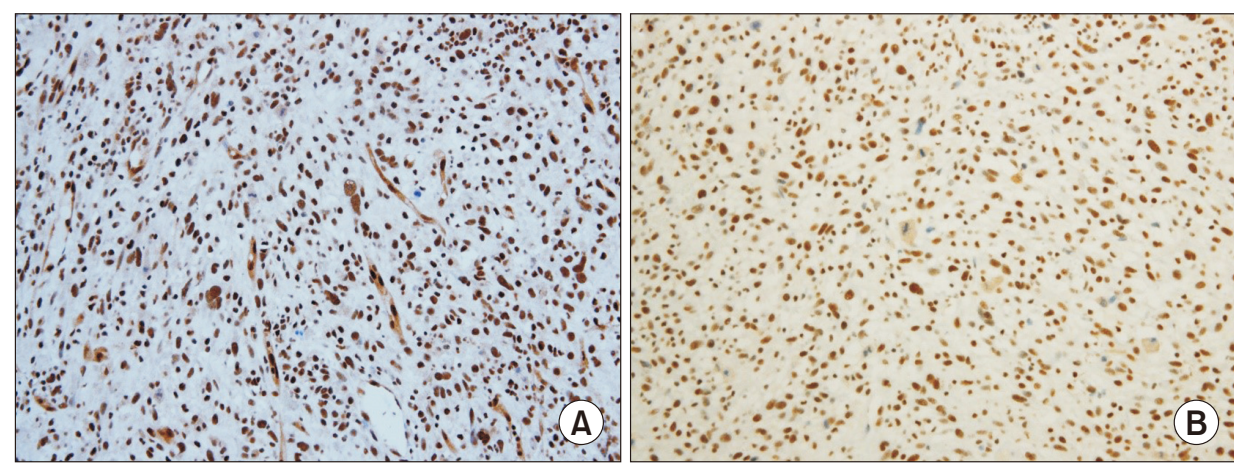

Fig. 4. A. The tumor cells are strongly positive for FLI-1 (x200). B. The tumor cells are strongly positive for $\mid \mathrm{NI}-1$ $(\times 200)$.

Tae-Ho Kim et al: Radiation-induced angiosarcoma (RIAS) of the maxilla: a case report. J Korean Assoc Oral Maxillofac Surg 2020 or mucoepidermoid carcinoma ${ }^{6}$.

Mucoepidermoid carcinoma is a malignant epithelial tumor commonly found in the salivary gland. The primary treatment modality for mucoepidermoid carcinoma is wide local resection in conjunction with neck dissection. RT is typically recommended for high-grade mucoepidermoid carcinomas. Although mucoepidermoid carcinoma diagnoses tend to show good overall prognosis, it is recommended that the postoperative follow-up period be as long as 10 years, due to the potential for late recurrence and regional metastasis ${ }^{7}$.

The typical histologic features of angiosarcomas include the presence of atypical endothelial cells in a number greater than required to line a vessel, as well as formation of vascular tubes with lamina that has a distinct tendency to anastomose with the delicate framework of reticulin fibers. Angiosarcomas also show rapid cell growth, local invasion, and early hematogenous spreading, which lead to poor prognosis.

Although treatment guidelines for angiosarcomas are currently minimal due to the limited number of literature reports, most authors advocate radical surgery. Because of the high risk of local recurrence, adjuvant RT in doses greater than 50 Gy is also recommended ${ }^{3}$. Other approaches support the use of primary RT, with surgery as an alternative or additional option $^{8-10}$. Despite the risk of metastasis, no clear evidence exists for use of chemotherapy as primary treatment or as a conjunctive treatment to surgery and primary RT. Although there is currently a lack of data advocating for chemotherapy as a treatment modality for angiosarcomas, chemotherapy can be considered in unresectable cases. Overall, there are also conflicting opinions on elective treatment of the neck ${ }^{10,11}$.

Radiation carcinogenesis is an unfortunate toxic consequence of cancer therapy, and sarcomas can be induced as a result of the ionizing radiation ${ }^{12}$. The exact pathogenesis of radiation-induced angiosarcoma is unknown. The $\mathrm{p} 53$ protein is known to play an important role in repairing radiationinduced DNA damage ${ }^{10,13}$. A previous study of spontaneous angiosarcoma in $\mathrm{p} 53$-null mice suggested that the $\mathrm{p} 53$ protein acts as a tumor suppressor gene and may thus be involved in angiosarcoma carcinogenesis ${ }^{10,14}$.

Our case represents a rare transformation of mucoepidermoid carcinoma into angiosarcoma following RT. RT, whether primary or adjuvant, enhances treatment outcomes and is preferable in many cases. However, rare complications such as malignant transformation are known to occur long after RT. Regular long-term follow-up is therefore crucial for patients with history of RT to prevent these complications.

\section{ORCID}

Tae-Ho Kim, https://orcid.org/0000-0002-8691-8028

Chul-Hwan Kim, https://orcid.org/0000-0002-5199-2420

Sang-Gyu Choi, https://orcid.org/0000-0002-8093-9493

\section{Author's Contributions}

T.H.K. participated in data collection and wrote the manuscript. C.H.K. and S.G.C. participated in the coordination and helped to draft the manuscript. All authors read and approved the final manuscript.

\section{Consent for Publishing Photographs}

Written informed consent was obtained from the patients for publication of this article and accompanying images.

\section{Conflict of Interest}

No potential conflict of interest relevant to this article was reported. 


\section{References}

1. Ramadhan A, Willén H, Thor A. Angiosarcoma of the mandible: Metastasis from a primary tumor of the right atrium of the heart. Case Reports in Clinical Medicine 2013;2:53-7. https://doi. org $/ 10.4236 / \mathrm{crcm} .2013 .21015$

2. Fomete B, Samaila M, Edaigbini S, Agbara R, Okeke UA. Primary oral soft tissue angiosarcoma of the cheek: a case report and literature review. J Korean Assoc Oral Maxillofac Surg 2015;41:273-7. https://doi.org/10.5125/jkaoms.2015.41.5.273

3. Doeuk C, McNamara Z, Taheri T, Batstone MD. Primary angiosarcoma of the mandible: a case report. J Oral Maxillofac Surg 2014;72:2499.e1-7. https://doi.org/10.1016/j.joms.2014.07.035

4. Yang XJ, Zheng JW, Zhou Q, Ye WM, Wang YA, Zhu HG, et al. Angiosarcomas of the head and neck: a clinico-immunohistochemical study of 8 consecutive patients. Int J Oral Maxillofac Surg 2010;39:568-72. https://doi.org/10.1016/j.ijom.2010.03.004

5. Anand VK, Arrowood JP Jr, Krolls SO. Malignant potential of the odontogenic keratocyst. Otolaryngol Head Neck Surg 1994;111:124-9. https://doi.org/10.1177/019459989411100122

6. Makowski GJ, McGuff S, Van Sickels JE. Squamous cell carcinoma in a maxillary odontogenic keratocyst. J Oral Maxillofac Surg 2001;59:76-80. https://doi.org/10.1053/joms.2001.19297

7. Rathore AS, Ahuja P, Chhina S, Ahuja A. Primary intraosseous mucoepidermoid carcinoma of maxilla. J Oral Maxillofac Pathol 2014;18:428-31. https://doi.org/10.4103/0973-029X.151339

8. Holden CA, Spittle MF, Jones EW. Angiosarcoma of the face and scalp, prognosis and treatment. Cancer 1987;59:1046-57. https://doi.org/10.1002/1097-0142(19870301)59:5<1046::aidcncr2820590533>3.0.co;2-6

9. Sagar SM, Pujara CM. Radical treatment of angiosarcoma of the scalp using megavoltage electron beam therapy. Br J Radiol 1992;65:421-4. https://doi.org/10.1259/0007-1285-65-773-421

10. Lydiatt WM, Shaha AR, Shah JP. Angiosarcoma of the head and neck. Am J Surg 1994;168:451-4. https://doi.org/10.1016/s00029610(05)80097-2

11. Mark RJ, Tran LM, Sercarz J, Fu YS, Calcaterra TC, Juillard GF. Angiosarcoma of the head and neck. The UCLA experience 1955 through 1990. Arch Otolaryngol Head Neck Surg 1993;119:973-8. https://doi.org/10.1001/archotol.1993.01880210061009

12. Lagrange JL, Ramaioli A, Chateau MC, Marchal C, Resbeut M, Richaud P, et al. Sarcoma after radiation therapy: retrospective multiinstitutional study of 80 histologically confirmed cases. Radiation Therapist and Pathologist Groups of the Fédération Nationale des Centres de Lutte Contre le Cancer. Radiology 2000;216:197205. https://doi.org/10.1148/radiology.216.1.r00j102197

13. Kuerbitz SJ, Plunkett BS, Walsh WV, Kastan MB. Wild-type p53 is a cell cycle checkpoint determinant following irradiation. Proc Natl Acad Sci U S A 1992;89:7491-5. https://doi.org/10.1073/ pnas.89.16.7491

14. Donehower LA, Harvey M, Slagle BL, McArthur MJ, Montgomery CA Jr, Butel JS, et al. Mice deficient for p53 are developmentally normal but susceptible to spontaneous tumours. Nature 1992;356:215-21. https://doi.org/10.1038/356215a0

\section{How to cite this article: $\mathrm{Kim} \mathrm{TH}$, Kim $\mathrm{CH}$, Choi SG. Radiation-} induced angiosarcoma (RIAS) of the maxilla: a case report. J Korean Assoc Oral Maxillofac Surg 2020;46:288-291. https://doi. org/10.5125/jkaoms.2020.46.4.288 